http://www.jumdc.com/

Original Article

\title{
A comparative study of postoperative airway management between traditional nasal packing and modified nasal airway after nasal surgeries
}

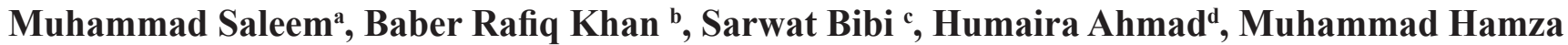 \\ Rana $^{\mathrm{e}}$ \\ ${ }^{a}$ Associate Professor, Department of Otorhinolaryngology Aziz Fatimah Medical \& Dental College, Faisalabad. \\ ${ }^{b}$ Associate Professor, Department of Otorhinolaryngology Faisalabad Medical University, Faisalabad. \\ ${ }^{c}$ Associate Professor, Department of Surgery Aziz Fatimah Medical \& Dental College, Faisalabad. \\ ${ }^{\mathrm{d}}$ Associate Professor, Department of Anesthesia, Faisalabad Medical University, Faisalabad. \\ ${ }^{\circ}$ Final Year MBBS Student, Aziz Fatimah Medical \& Dental College, Faisalabad. \\ *Corresponding author: drsaleementspt@gmail.com
}

\section{ABSTRACT}

BACKGROUND \& OBJECTIVE: One of the most common challenging complications after nasal surgeries is maintaining airways. The study aimed to use an alternative technique instead of nasal packing in the immediate postoperative period undergoing different nasal surgery under general anesthesia regarding airway management.

METHODOLOGY: An interventional study was conducted at Aziz Fatimah Trust Hospital, Faisalabad, from March 20, 2018, to January 31, 2019. A total of 100 participants were enrolled in the study divided into two groups (A \& B), 50 each. Group A patients were treated postoperatively with a modified nasal airway devised with a Nelton catheter and Group B patients with traditional nasal packing. The participants were assessed on different parameters which were statistically compared and analyzed.

RESULTS: Group Descriptive statistics revealed that the Mean \pm SD of the age of group A and group B patients was $24.28 \pm 9.72$ and $26.68 \pm 11.09$ respectively, which had no significant difference between them $\{\mathrm{p}$-value $(0.008)\}$. The postoperative parameters such as patient's comfort and sleep, surgeon satisfaction, ease of suction through Nelton catheter, and oxygen saturation were evaluated as significant variables in the evaluation of the study. p-value $\leq 0.05$ and $\leq 0.005$ were considered as significant and highly significant respectively.

CONCLUSION: This modified nasal airway has proven to be easily replicable and reliable, and a cost-effective measure elucidated as a potential and exclusive outcome of the present study.

KEYWORDS: Airway obstruction, Airway patency, Nasal surgery, Nasal airway, Nasal packing, Nelton catheter.

\section{INTRODUCTION}

Airway obstruction after head \& neck surgery is the most common known complication. For various pathologies of the nose and paranasal sinuses, Functional endoscopic sinus surgery (FESS) and conventional surgeries widen the nasal cavity and promote paranasal sinus drainage ${ }^{[1,2]}$. The primary aim and the basic principle of nasal surgery are to relieve nasal obstruction, improve nasal patency and induce mucociliary clearance ${ }^{[3]}$. Besides these complications such as orbital trauma, Cerebrospinal fluid (CSF) leak, secondary infections, hematoma, postoperative adhesions, and crusting, various other complications including aspiration, embolism, nausea, and vomiting, myocardial infraction, airway edema, and obstruction can also precipitate postoperative complications ${ }^{[4]}$. The obstructive element can be so severe that it may need re-intubation for the patient's lifesaving and airway maintenance. Any condition that causes mild to moderate obstruction in breathing, including the therapeutic blockage with nasal packing in epistaxis, can cause significant discomfort ${ }^{[5]}$. Untreated blockage can produce fatal, life-threatening consequences such as dyspnea, rapid hypoxemia, and carbon dioxide retention. The preoperative counseling about breathing through the mouth may sometimes not produce the desired result, and anesthetists usually face difficulty establishing patent airway postoperatively as the patients are under the influence of follow-up medications. With such prevailing conditions,

Saleem M, Khan BR, Bibi S, Ahmad H, Rana MH. A comparative study of postoperative airway management between traditional nasal packing and modified nasal airway after nasal surgeries. Journal of University Medical \& Dental College.2022;13(1):304-308. 
it is challenging to assess the recovery profile during the postoperative period ${ }^{[6]}$.

Pakistan is a developing country. Most people visiting these health care centers belong to a low socioeconomic class. Hence provision of expensive airways is not feasible. While considering these limitations and potential complications, we designed a novel intervention to maintain the airway postoperatively in-patient undergoing nasal surgery conventional and advanced Functional Endoscopic Sinus Surgeries (FESS) under general anesthesia. To prevent airway obstruction and breathing discomfort, the intervention aimed at using the cost-effective sterilized Nelton catheter, cut in an appropriate size, and placed in the nasal cavity with fixing it with 2.0 black silk anteriorly behind the columella with membranous part of the septum after completion of the surgical procedure.

All the data collected was analyzed in SPSS 20 using CHI square test. P-value $\leq 0.05$ was considered to be significant, while $\mathrm{p} \leq 0.001$ was highly significant.

\section{METHODOLOGY}

An interventional study from March 20, 2018, to January 31,2019 , was conducted after taking ethical approval under no. DME/ 385-18 from the institutional ethical committee of Aziz Fatimah Medical and Dental college Faisalabad at Aziz Fatimah Hospital Faisalabad. 100 patients who underwent functional endoscopic sinus surgeries and conventional nasal surgeries were selected using the purposive sampling technique ${ }^{[1]}$.

Patients were divided into two groups and allocated as group A and group B consisting of 50 patients each. Group-A included patients with modified nasal airway devised with Nelton catheter, and Group B comprised patients with traditional nasal packing postoperatively. After briefly explaining the procedure, the participants were added to either group after their consent. The age of the sample population included in both groups ranges between 15-55 years of either gender. Patients with ischemic heart disease and a history of CNS disorder were excluded from the study. After fulfilling the surgery prerequisites and planned airway intervention to avoid any respiratory obstruction postoperatively, written consent was taken from the patients. Patients of group-B were counseled thoroughly about mouth breathing after the surgery.

Patients were admitted one day before surgery for investigation and preoperative evaluation. The patients were given a dose of alprazolam $(0.25 \mathrm{mg}$, oral) a night before the surgery. In Operation Theatre, general anesthesia was induced with standard techniques using Propofol, Suxamethonium for intubations and maintained with oxygen nitrous oxide and $0.2-1.5 \%$ Forane with a longacting muscle relaxant. The Vitals of the participants from both groups were under constant monitoring and recorded after every 10 -minute interval.

In group A patients, before nasal packing, a pre-sterilized Nelton catheter was cut to an appropriate size and placed in each nostril at the end of the surgery (Figure-I). The distal end was kept at the choana's posterior aspect, and the anterior end was fixed anteriorly with the membranous part of the septum with 2.0 black silk. Moderate anterior nasal packing was done around the tube (Figure-II).

On the other hand, traditional nasal packing was done in Group-B patients. (Figure-III) After completing the surgery, patients were reversed from the anesthesia, extubated as they became fully conscious, and sustained a regular breathing pattern.

Patients of both groups were kept in the recovery room for 2 hours in a partial propped-up position under close observation with particular attention to the respiratory mechanics and partial oxygen pressure. Patients were inquired about the postoperative parameters for the next 24 hours, including monitoring and recording the immediate partial oxygen pressure in the recovery room, sleep pattern, patient comfort, respiratory distress, ease of suction through the airway, surgeon and anesthetist satisfaction, bleeding, the removal of nasal packing, and airway. The statistical analysis was done using SPSS 20 . The continuous variables like age bis presented as $\mathrm{X} \pm \mathrm{SD}$, and means between the study groups by independent t-test. The categorical variables such as gender and the postoperative parameters were expressed as frequency and percentages. A Chi-square test was used to compare the proportions of the responses. $p$-value $\leq 0.05$ was taken as significant and $\leq 0.001$ as highly significant.

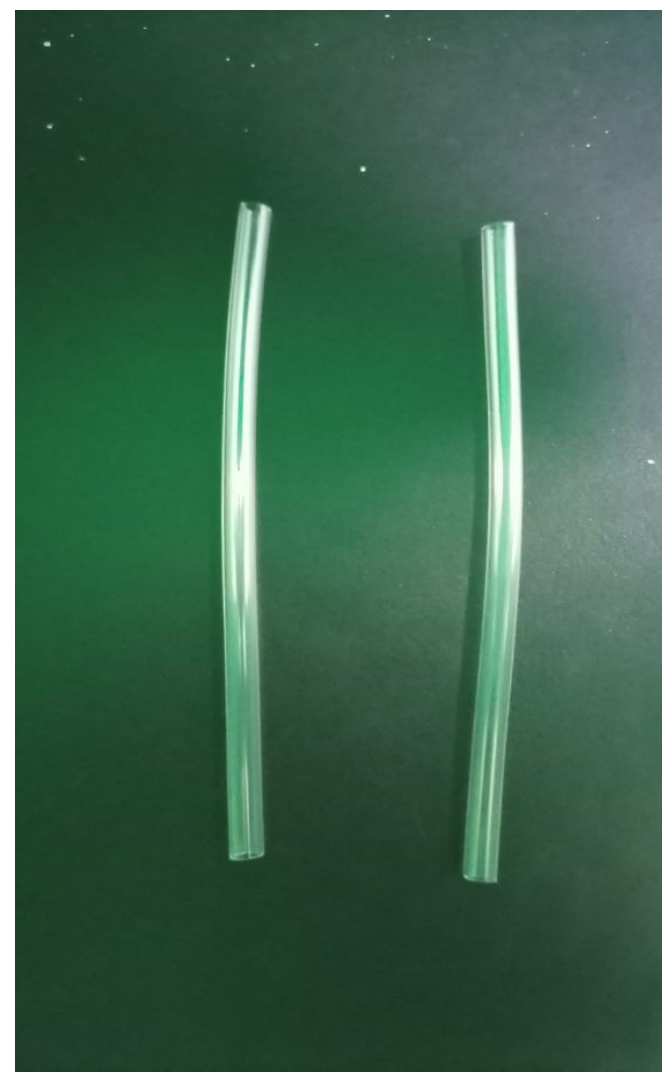

Figure-I: Nelton Catheter cut in an appropriate size. 


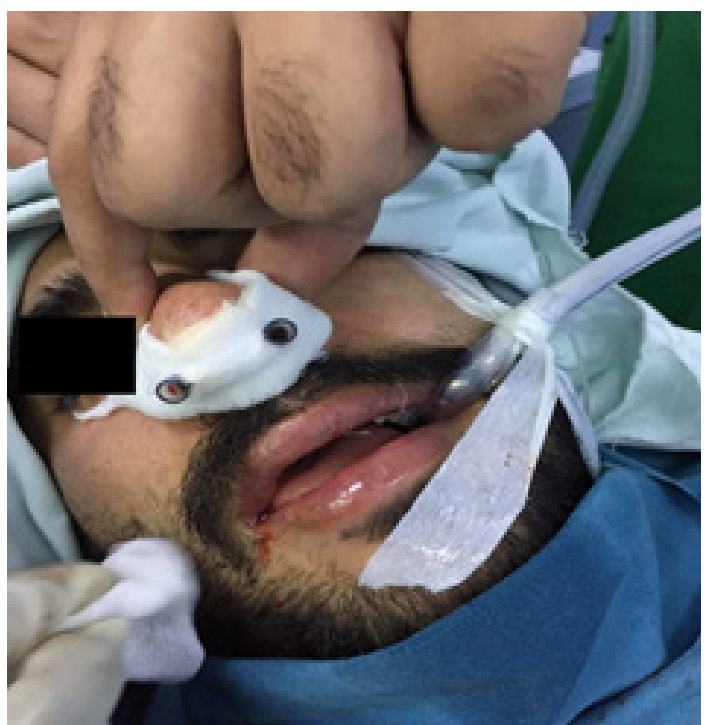

Figure-II: Modified Nasal airway with Nelton catheter.

\section{RESULTS}

A total of 100 patients, divided into two groups, 50 each were administered general anesthesia for Functional endoscopic sinus surgery (FESS) during the study period. Group A comprised 28 males and 22 females, while on the other

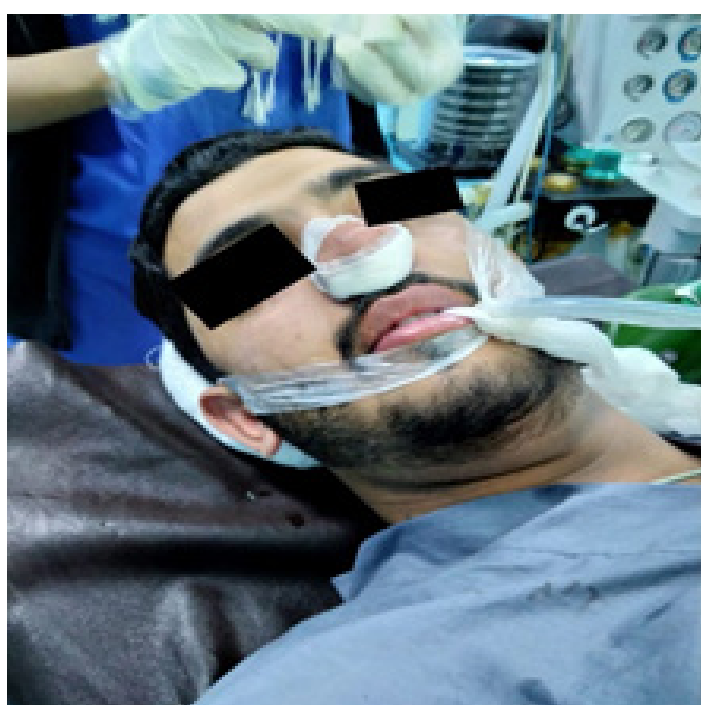

Figure-III: Traditional nasal packing.

hand, 34 males and 16 females were included in Group-B. Descriptive statistics is used for exploring the characteristics of variables. Mean $\pm \mathrm{SD}$ of the age of group 1 and group 2 patients was $24.28 \pm 9.72$ and $26.68 \pm 11.09$, respectively. A two tailed p-value states no significant difference in the mean age of both groups $\{p$-value $(0.2526)\}$.

Table-I: Comparison of Postoperative parameters among Group A (Modified nasal airway with Nelton catheter) and Group B (Traditional nasal packing) N=100.

\begin{tabular}{|c|c|c|c|c|}
\hline $\begin{array}{c}\text { Post Operative parameters/ } \\
\text { variables }\end{array}$ & Responses & Group-A $(n=50 \%)$ & Group-B $(n=50 \%)$ & p-value \\
\hline \multirow[t]{2}{*}{ Respiratory Distress Complaint } & Yes & $4(8)$ & $18(36)$ & $<0.001 *$ \\
\hline & No & $46(92)$ & $32(64)$ & \\
\hline \multirow[t]{2}{*}{ Oxygen saturation after extubation } & Saturation above $96 \%$ & $48(96)$ & $40(80)$ & $0.014 *$ \\
\hline & Saturation below $96 \%$ & $2(4)$ & $10(20)$ & \\
\hline \multirow[t]{2}{*}{ Patient comfort and sleep pattern } & $\begin{array}{l}\text { No complaint of disturbed sleep and } \\
\text { comfort }\end{array}$ & $43(86)$ & $9(18)$ & $<0.001 * *$ \\
\hline & Patient comfort and sleep disturbed & $7(14)$ & $41(82)$ & \\
\hline \multirow[t]{2}{*}{ Ease of suction throughout the airway } & Easily accessible & $47(94)$ & $11(22)$ & $<0.001 * *$ \\
\hline & Difficulty in suction & $3(6)$ & $39(78)$ & \\
\hline \multirow[t]{2}{*}{ Surgeon and anesthetist satisfaction } & Satisfactory & $49(98)$ & $15(30)$ & $<0.001 * *$ \\
\hline & Not Satisfactory & $1(2)$ & $35(70)$ & \\
\hline \multirow[t]{2}{*}{$\begin{array}{c}\text { Any bleeding during removal of nasal } \\
\text { packing }\end{array}$} & Bleeding present & $2(4)$ & $3(6)$ & 0.64 \\
\hline & Bleeding absent & $48(96)$ & $47(94)$ & \\
\hline
\end{tabular}

$\mathrm{p} \leq 0.05=$ Significant $^{*}, \mathrm{p} \leq 0.001=$ Highly Significant $* *$

\section{DISCUSSION}

Various techniques have been used to avoid any complications during Head, Neck, and Nasal surgery, with varied success at different times ${ }^{[7]}$. However, the vital aspect keeping in mind while doing this intervention is the cost-effectiveness, especially in developing countries like Pakistan, and the availability of such equipment. The laryngeal airway has been used successfully, and the nasopharyngeal airway can also serve as an excellent conduit for maintaining the nasal airway patency postoperatively. Nevertheless, the high cost will limit its application and benefits in developing nations with struggling socioeconomic status ${ }^{[8]}$. In the present study, we investigated the benefits of using the low-cost modified airway, a pre-sterilized Nelton catheter of appropriate size per the nasal cavity of patients undergoing nasal surgery under general anesthesia over traditional nasal packing. 
In most patients, it is challenging to maintain normal airway breathing through the mouth after bilateral nasal packing postoperatively despite counseling preoperatively ${ }^{[9,10]}$. During the present study, patients were monitored for 2 hours in recovery and 22 hours in the ward, emphasizing oxygen saturation, respiratory distress, patient discomfort vitals, and general consciousness. Besides the potential known complications, this study elucidates the benefits of a modified nasal airway, maintains the regular breathing pattern with normal oxygen saturation, and highlights the right role of maintaining cardiac parameters to reduce hypoxemia respiratory risk obstruction.

One of the challenging obstacles to overcome is maintaining respiratory comfort for the patients who underwent surgery. The nasal packs compel the patient to breathe through the mouth, leading to respiratory distress and dropping the patient's oxygen saturation level. Low oxygen saturation can lead to severe complications. However, in our study, only $8 \%$ complained of respiratory distress problem treated postoperatively with modified nasal airway management with Nelton catheter in group A while 18 patients (36\%) reported being suffering from respiratory distress problem in group-B. $p$-value $\leq 0.001$ suggest the variable to be statistically significant and states that the present interventional study has positive outcomes.

Poor nasal airway patency renders the patients with chronic obstructive pulmonary disease, Obstructive sleep apnea, and cardiovascular anomalies with disrupted respiratory mechanics. Oxygen saturation levels can fluctuate to significant levels. The chances of complications with respiratory distress and oxygen saturation failure are significantly increased when anesthesia and sedation are deep. The postoperative period in such patients can be too stormy if they cannot breathe through the mouth ${ }^{[11]}$. Oxygen saturation was recorded, monitored, and analyzed as only two patients $(4 \%)$ reported oxygen saturation levels below 96 percent in Group A patients. On the other hand, in group-B patients, 10 patients were summited with oxygen saturation levels below 96 percent. p-value indicates the variable to be significant statistically.

The present intervention stated that patient comfort and sleep pattern with the Nelton catheter during the postoperative period were crucial factors to be highly decisive in designing the study. $14 \%$ of participants in group-A with Nelton catheter as the modified airway postoperatively responded with significantly low pain and discomfort with regular sleep patterns. On the other hand, $82 \%$ of patients complained of disturbed sleep and comfort in group B patients. The application of tranquilizers aided the disturbed patient comfort and sleep pattern. Our study stated this variable to be statistically significant.

According to our study, patients with modified nasal airways support a more easy and convenient approach to suction throughout the airway. Removal of nasal packing is excruciating and sometimes requires sedation or short anesthesia in a very anxious patient. In this study, The ease of suction through the nasal airway is another advantage of this present intervention. Similar results were found in the study conducted by Cayonu M. ${ }^{[12]}$. The most probable cause of such happening is the absorption of blood and fluid by the phalangeal throat pack during the surgical period ${ }^{[13,14]}$. Previous studies state that patients with nasal polyp are associated with the Samster triad is about $5 \%$. Thus, removing nasal packing in such patients results in bronchospasm in response to drugs like aspirin and NSAID ${ }^{[15]}$. According to our study, no such statistical difference was recorded associated with a bleeding problem in the present study.

The present intervention's subjective assessment was carried out among the surgeon, anesthetist, and the patient who underwent nasal surgeries. Postoperative variables include patient comfort and sleep pattern, respiratory distress, oxygen saturation, and bleeding on removing nasal packing with surgeon and anesthetist satisfaction. The survey observed that the present intervention satisfies $98 \%$ of anesthetists and surgeons with modified nasal airway management.

\section{CONCLUSION}

This intervention proved to ve very efficacious. Besides the patent airway, the additional benefits include ease of suctioning through the airway, oxygen supplementation whenever needed, a possible hemostatic effect due to pressure of Nelton catheter on the operated site, the minimum chance of adhesion formation postoperatively.

\section{ACKNOWLEDGMENT:}

We are grateful to Dr. Shireen Jawad (Associate Professor Physiology, Aziz Fatimah Medical \& Dental College Faisalabad) for guiding and adding intellectual content in the study.

\section{CONFLICT OF INTEREST: None.}

GRANT SUPPORT AND FINANCIAL DISCLOSURE: It is hereby stated that this research article is not presented at any conference or submitted to any other journals.

\section{REFERENCES:}

1. Bajwa SJ, Kaur J, Singh A, Parmar SS, Singh S. Postoperative airway management after nasal endoscopic sinus surgery: A comparison of traditional nasal packing with nasal airway. Anesthesia, essays and researches. 2013;7(1):116-122. Doi:10.4103/02591162.114017.

2. Nakagawa $Y$, Ishii H, Nomura $Y$, Watanabe NY, Hoshiba D, Kobayashi K, Ishibashi K. Third molar position: reliability of panoramic radiography. Journal of oral and maxillofacial surgery. 2007;65(7):13031308. Doi:10.1016/j.joms.2006.10.028

3. Tripathi PB, Majd P, Ngo T, Gu JT, Sharma GK, Badger C, et al. Evaluation of Safety and Efficacy for an Intranasal Airway Device in Nasal Surgery. JAMA facial plastic surgery. 2019;21(1):38-43. Doi:10.1001/ jamafacial.2018.0955

4. Lipan MJ, Most SP. Development of a severity classification system for subjective nasal obstruction. JAMA facial plastic surgery. 2013;15(5):358-361. Doi:10.1001/jamafacial.2013.344 
5. Zhang F, Chen J, Lei X, Chen X, Zhang X. The comfort of patients with different nasal packings after endoscopic sinus surgery for chronic rhinosinusitis: A protocol for network meta-analysis. Medicine. 2019;98(24): e16007. Doi: 10.1097/MD.0000000000016007

6. Mehta VM, Har-El G, Goldstein NA. Postobstructive pulmonary edema after laryngospasm in the otolaryngology patient. The Laryngoscope. 2006;116(9):1693-1696. Doi:10.1097/01. mlg.0000231762.91541.3a

7. Athanassoglou V, Patel A, McGuire B, Higgs A, Dover MS, Brennan PA. Systematic review of benefits or harms of routine anaesthetist-inserted throat packs in adults: practice recommendations for inserting and counting throat packs: An evidence-based consensus statement by the Difficult Airway Society (DAS), the British Association of Oral and Maxillofacial Surgery (BAOMS) and the British Association of Otorhinolaryngology, Head and Neck Surgery (ENT-UK). Anaesthesia. 2018;73(5):612-618. Doi. org/10.1111/anae.14197

8. Yeniay D, Çekiç B. Comparison of the ProSeal laryngeal mask airway and endotracheal tube in septorhinoplasty surgery. Cukurova Medical Journal.2021;46(4):1468-1477.

Doi:10.17826/ cumj. 978120

9. Moubayed SP, Ioannidis JP, Saltychev M, Most SP. The 10-item Standardized Cosmesis and Health Nasal Outcomes Survey (SCHNOS) for functional and cosmetic rhinoplasty. JAMA facial plastic surgery. 2018;20(1):37-42. Doi: 10.1001/jamafacial.2017.1083

10. Ishii LE, Tollefson TT, Basura GJ, Rosenfeld RM, Abramson PJ, Chaiet SR, et al. Clinical practice guideline: improving nasal form and function after rhinoplasty. Otolaryngology-Head and Neck Surgery. 2017;156(2_suppl):S1-30.

11. Hamans EP, Van Marck EA, De Backer WA, Creten W, Van de Heyning PH. Morphometric analysis of the uvula in patients with sleep-related breathing disorders. European archives of oto-rhino-laryngology. 2000;257(4):232-236. Doi:10.1007/s004050050229

12. Cayonu M, Acar A, Horasanlı E, Altundag A, Salihoglu M. Comparison of totally occlusive nasal pack, internal nasal splint, and transseptal suture technique after septoplasty in terms of immediate respiratory distress related to anesthesia and surgical complications. Acta oto-laryngologica. 2014;134(4):390-394. Doi. org/10.1177/0194599816683153

13. Tabboush ZS. Airway obstruction from uvular edema after traumatic adenoidectomy. Anesthesia \& Analgesia. 2000;91(2):494. Doi:10.1097/00000539-20000800000050

14. Gandhi R. Postoperative uvular edema after general anesthesia in an adult patient. Ain-Shams Journal of Anesthesiology. 2018;10(1):1-3. Doi:10.1186/s42077018-0007-5
15. Kim JE, Kountakis SE. The prevalence of Samter's triad in patients undergoing functional endoscopic sinus surgery. Ear, Nose \& Throat journal. 2007;86(7):396399. Doi:10.1177/014556130708600715

\section{Author's Contribution:}

Muhammad Saleem: Study Design, data collection, and manuscript writing.

Baber Rafiq Khan: Study design, manuscript writing, and literature Review.

Sarwat Bibi: Result Analysis, final revision \& critical review.

Humaira Ahmad: Study design, manuscript writing. Muhammad Hamza Rana: Manuscript writing, critical review.

Submitted for publication: 26-08-2021

Accepted after revision: 12-01-2022 